\title{
POPPER E O PROCESSO DE ENSINO-APRENDIZAGEM PELA RESOLUÇÃO DE PROBLEMAS
}

\author{
Horácio Wanderlei Rodrigues
}

POPPER AND THE TEACHING-LEARNING PROCESS

FOR TROUBLESHOOTING

\section{RESUMO}

O ARTIGO PROPÕE UM MÉTODO DE ENSINO E UMA ESTRUTURA CURRICULAR CONSTRUÍDOS COM BASE NA OBRA EPISTEMOLÓGICA DE Karl Popper e também em elementos presentes no Problem Based LeARning (PBL). O processo de Ensino-AprendizAgem PEla Resolução de Problemas (EARP) apresentado neste trabalho está divido em Método EARP e Projeto Pedagógico EARP. NO PLANO DO MÉTODO A PROPOSTA ESTÁ CENTRADA EM UMA ESTRATÉGIA COMPOSTA DE QUATRO ETAPAS, TODAS ELAS ENVOLVENDO O ESTUDO DE PROBLEMAS, BUSCANDO A SUA SOLUCC̃O POR MEIO DE TENTATIVAS E ELIMINAÇÃO DE ERROS. NO PLANO DO PROJETO PEDAGÓGICO A PROPOSTA INCLUI A ELIMINACÃO DA TRADICIONAL ORGANIZAÇÃO DO CURRÍCULO POR DISCIPLINAS E APRESENTA UMA ESTRUTURA MODULAR POR GRANDES TEMAS INTERDISCIPLINARES. O TEXTO CONTÉM, PARA MELHOR VISUALIZACÃO DA PROPOSTA, UMA GRADE HIPOTÉTICA E AS POSSIBILIDADES DE ORGANIZAÇÃO DO QUADRO DE HORÁRIOS.

\section{PALAVRAS-CHAVE}

ENSINO DO DIREITO; ENSINO JURÍDICO; CURSO DE DIREITO; CURSO JURÍDICO; ENSINO-APRENDIZAGEM; MÉTODO; CURRí́Culo; CRÍTICA; KARL POPPER; PBL.

\section{ABSTRACT}

THE PAPER PROPOSES A METHOD OF TEACHING AND A CURRICULUM STRUCTURE CONSTRUCTED ON THE EPISTEMOLOGICAL WORK OF KARL POPPER AND ALSO ELEMENTS IN PROBLEM BASED LEARNING (PBL). THE TEACHING-LEARNING PROCESS FOR TROUBLESHOOTING (EARP) PRESENTED IN THIS PAPER IS DIVIDED INTO METHOD AND PEDAgOgICAL PROJECT (EARP). THE PROPOSED METHOD FOCUSES ON A STRATEGY CONSISTING OF FOUR STAGES, ALL INVOLVING THE STUDY OF ISSUES, SEEKING A SOLUTION THROUGH TRIAL AND ELIMINATION OF ERRORS. THE Pedagogical PROJect includes the elimination of TRADITIONAL DISCIPLINES BY ORGANIZING THE CURRICULUM AND HAS A MODULAR STRUCTURE FOR INTERDISCIPLINARY TOPICS. THE TEXT CONTAINS, FOR BETTER VISUALIZATION OF THE PROPOSAL, A HYPOTHETICAL GRADE AND THE POSSIBILITIES OF ORGANIZING TIME FRAME.

\section{KEYWORDS}

TEACHING OF LAW; LEGAL EDUCATION; LAW COURSE; LEGAL COURSE; TEACHING AND LEARNING; METHOD; CURRICULUM; CRITICAL; KARL POPPER; PBL.

\section{UMA PROPOSTA PARA REPENSAR O ENSINO DO DIREITO - O PROCESSO de ensino-APRendizagem Pela Resolução de Problemas (EARP)}

Senti a necessidade de esboçar a proposta contida neste artigo à medida que lia a obra de Karl Popper, no decorrer da qual o autor procura demonstrar, a cada momento, que nosso aprendizado, em todas as áreas e atividades, dá-se por tentativa e erro, na busca da resolução de problemas. 
A proposta que apresento para o processo de ensino-aprendizagem dos cursos de direito contém: (a) uma nova forma de organizar seus conteúdos e suas atividades; e (b) uma nova forma de trabalhar esses conteúdos e essas atividades com os alunos, em sala de aula ou fora dela. Trata, portanto, do projeto pedagógico dos cursos e das estratégias didático-pedagógicas a serem utilizadas.

Denominei-a provisoriamente Ensino-Aprendizagem pela Resolução de Problemas (EARP), dividida em Método EARP - objeto da parte 2 deste artigo - e Projeto Pedagógico EARP - ao qual está destinada a parte 3.

\section{Primeiro Passo: Mudar as estratégias didÁtico-Pedagógicas - o método de Ensino-Aprendizagem pela Resolução de Problemas}

O tema das estratégias de ensino-aprendizagem - as metodologias ou técnicas didáticas - é sempre presente quando se trabalha educação, afinal escolhas acertadas podem facilitar a aprendizagem do aluno, permitindo-lhe uma melhor compreensão dos conteúdos e o desenvolvimento das adequadas competências e habilidades.

Nos cursos de direito a tradição centenária é a utilização da aula-conferência - a atual aula expositiva. A aula expositiva pode conter, mesmo que implicitamente, um conjunto de problemas os quais tornam questionável a sua adoção como único ou principal instrumento do processo de ensino-aprendizagem: ela centraliza o conhecimento na figura do professor, possibilita o ensino dogmático e a reprodução acrítica de qualquer conhecimento, reduz a possibilidade da análise crítica e da participação ativa dos alunos, viabiliza de forma mais efetiva o convencimento emocional e/ou ideológico, através do discurso bem elaborado e da boa interpretação do papel docente - apenas para citar alguns dos riscos existentes quando de sua inadequada utilização.

Essa estratégia, embora não deva ser excluída do leque de possibilidades didáticopedagógicas - é necessário reconhecer a sua grande utilidade como instrumento informativo e sistematizador do conhecimento -, não pode permanecer como praticamente a única empregada. Mesmo a sua utilização em conjunto com algumas estratégias interacionistas, como os trabalhos em grupo, não é suficiente para propiciar o aprendizado adequado às necessidades do mundo contemporâneo. De outro lado, a sua substituição pelos impropriamente denominados seminários - nada mais do que painéis ou aulas expositivas ministradas pelos próprios alunos - é ainda mais inadequada.

Buscando encontrar uma alternativa viável para esse problema didático-pedagógico, nesta seção vamos apresentar o Método EARP. Ele será descrito em dois momentos distintos - o primeiro será dedicado ao elemento principal do método, o problema, e o segundo, ao método de estudo propriamente dito.

\section{I O PRoblema Como elemento Central do MÉtodo EARP}

Frequentemente, quando se fala em utilizar problemas como elementos de estruturação 
de um processo de ensino-aprendizagem na área do direito, identifica-se problema como sendo caso prático - o que leva, quase invariavelmente, a identificar o método de Ensino-Aprendizagem pela Resolução de Problemas com a metodologia do estudo de casos. Reside aí um erro que necessita ser eliminado de início.

O Método EARP é uma abordagem dedutiva, ao passo que o estudo de casos é, na sua forma mais comum, uma abordagem indutiva (o que pode ser considerado, pelo menos em parte, adequado na realidade dos EUA, onde o sistema jurídico é o common law, baseado no precedente judicial, mas muito perigoso no Brasil, que adota o modelo continental, de supremacia da norma escrita).

Quando se parte de um problema genérico, que pode ser teórico ou prático, e se constroem hipóteses explicativas (teorias, conjecturas), estabelecem-se possibilidades das quais são deduzidas as consequências práticas - esse processo permite refutar aquelas hipóteses que, se aceitas, levariam a resultados inadequados ou indesejáveis. Através desses testes - tentativa e erro, nova tentativa, e assim sucessivamente - é possível uma aproximação da verdade, que Popper chama de verossimilitude, permitindo a corroboração da melhor hipótese entre as testadas.

Quando se parte do caso, a tendência é buscar a generalização da resposta dada ao caso estudado - em regra geral, um caso considerado paradigmático - para os demais casos similares. E essa postura indutiva desconsidera, em muitos momentos, que a adoção de uma determinada interpretação, em detrimento de outras, é sempre passível de revisão quando o conhecimento avançar e corroborar novas hipóteses - quando uma nova teoria testada apresente melhores resultados comparativamente com suas concorrentes.

Isso não significa que não se possa ou deva realizar estudo de casos, mas se deve ter claro que o caso apenas adquire sentido como teste empírico de uma hipótese explicativa, ou seja, os casos estudados devem ser vistos apenas como testes de hipóteses teóricas: os casos são apenas testes empíricos de uma hipótese proposta como solução de um problema.

Provavelmente outras hipóteses já terão sido propostas e outras mais virão a ser apresentadas. Algumas delas também já foram testadas em outros casos. Nesse contexto, o caso deve ser estudo de forma crítica, buscando refutar as soluções apresentadas. E não se deve ficar apenas nas hipóteses explicativas apresentadas no caso; é necessário buscar ou mesmo criar outras. Será através desse processo de tentativas e erros que as hipóteses concorrentes irão sendo refutadas e se terá uma (ou mais de uma) corroborada, aceita como a aproximação possível da verdade relativamente àquele problema.

O elemento central do método proposto, como adequadamente justificado, são os problemas - deve-se preparar o aluno para solucionar problemas, permitindo que ele busque as respostas através dos diversos meios de difusão do conhecimento hoje disponíveis, aprendendo a utilizá-los. O objetivo de cada problema é suscitar uma 
discussão produtiva no grupo de alunos; o processo de ensino-aprendizagem, em especial em nível universitário, não pode se restringir em dar a conhecer os fatos e as teorias. Como destaca Popper (2002):

A fim de entendermos o conteúdo de uma teoria, em primeiro lugar é necessário compreender o problema que ela procura solucionar; e compreender também as diversas tentativas feitas de resolução, ou seja, as diferentes teorias rivais. (p. 162)

Popper afirma, em seu livro Conjecturas e refutações, que devemos estudar problemas, não matérias - problemas que podem ultrapassar as fronteiras de qualquer matéria ou disciplina -; a realidade não se manifesta em conceitos, mas através de problemas. Sua afirmação mais geral, de que o conhecimento não parte de observações, mas sempre de problemas, está presente em praticamente toda a sua obra.

$\mathrm{Na}$ proposta apresentada neste artigo, cada problema é proposto para o desenvolvimento dos estudos sobre um tema específico do currículo. Esse tema é parte de um módulo temático, juntamente com outros temas afins. O problema tem de estar relacionado intimamente ao tema que se quer desenvolver, de modo que sua discussão conduza o grupo ao aprofundamento de seus conhecimentos sobre ele. Um bom problema deve ter as seguintes qualidades (UEL, 2005):

a) Ser simples e objetivo, evitando pistas falsas que desviem a atenção (do grupo) do tema principal. Um enunciado muito complexo propõe muitas situações-problema em seu interior, torna difícil a visualização da questão principal proposta e deságua em um número muito grande de objetivos de aprendizado, desmotivando o estudo. b) Ser motivador, despertar o interesse do aluno pela sua discussão. Um bom problema deve propor situações sobre as quais o aluno já tenha algum conhecimento prévio. Os primeiros problemas de um módulo temático devem referir-se a situações que os alunos já tenham vivenciado na prática, em sua própria vida ou em módulos temáticos anteriores. Uma situação totalmente nova e desconhecida impede a discussão do grupo já que nenhum de seus membros poderá oferecer qualquer contribuição para seu conhecimento.

Um problema mal formulado compromete todo o processo; um problema bem formulado deve contribuir para que os grupos de trabalho elejam objetivos de aprendizado análogos aos imaginados por quem o elaborou, como necessários para o crescimento cognitivo do grupo relativamente àquele tema específico.

O professor deve ter claro o que pretende com o problema e que objetivos de aprendizado os alunos devem atingir com a sua resolução. Aos alunos devem ser disponibilizados o enunciado e as referências dos recursos educacionais disponíveis - 
bibliografia, recursos audiovisuais (vídeos, filmes), endereços de páginas da internet etc. - que possam ajudá-los na busca de soluções para o problema.

\subsection{O MÉTODO EARP}

O Método EARP é uma estratégia didático-pedagógica de cunho eminentemente interativo e crítico. Foi elaborado com base no esquema popperiano de aprendizagem por tentativa e erro e nas estratégias pedagógicas utilizadas pelo Problem Based Learning (PBL), ${ }^{1}$ com as quais não se confunde.

O método proposto pode ser utilizado, nos projetos pedagógicos tradicionais, como estratégia pedagógica individual, em cada disciplina, ou mesmo para pontos específicos de uma disciplina. Entretanto, sua utilização será mais produtiva no contexto de um Projeto Pedagógico EARP - que será apresentado na parte 3 deste artigo.

\subsection{A TENTATIVA E O ERRO - A PROPOSTA POPPERIANA}

Popper acreditava que analisar a produção do conhecimento deveria ser o papel principal da filosofia - para ele, o estudo do método pela Teoria do Conhecimento ou Epistemologia é o objeto central da Filosofia. Em vários trabalhos nessa área, externou sua proposta, que ele mesmo resumia no esquema quadripartido apresentado a seguir. Com tal esquema, Popper substitui a tradicional busca pelas fontes do conhecimento pela busca pela descoberta e eliminação de erros.

$$
P_{1} \rightarrow T E \rightarrow E E \rightarrow P_{2}
$$

No esquema, $P_{1}$ é o problema inicial, TE é a teoria explicativa, hipótese ou conjectura, EE é a experiência empírica (incluindo a observação) e $P_{2}$ é o novo problema, oriundo dos resultados da experiência (na realidade podem ser vários novos problemas: $P_{2}, P_{3}, P_{4}$, e assim sucessivamente).

O esquema global indica que partimos de um problema, quer de natureza prática quer teórica; tentamos resolvê-lo elaborando uma teoria possível na qualidade de solução possível - é o nosso ensaio; em seguida, ensaiamos a teoria, procurando fazê-la abortar - é o método crítico de eliminação de erros; em resultado desse processo surge um novo problema, $P_{2}$ (ou, quem sabe, vários novos problemas) [...] Resumindo, o esquema diz-nos que o conhecimento parte de problemas e desemboca em problemas (até onde for possível ir). (POPPER, 2002, p. 23, grifo do autor)

Segundo Popper (1980), aprendemos fundamentalmente com nossos erros, porque, embora a ciência, assim como a tecnologia, não possam nos indicar aquilo que 
pode ser concretizado, elas podem "apontar aquilo que não pode ser concretizado" (p. 49) - "seleção por eliminação" (p. 108).

Nesse contexto, a ideia popperiana de refutação merece algumas palavras ao se pensar especificamente na área de direito. Ao trabalharmos com a resolução de problemas por tentativa e erro, eliminando gradativamente os resultados equivocados, não poderemos chegar à verdade, mas nos aproximaremos dela. Além disso, teremos um aprendizado fundamental nesse processo, que é o de crítica: na área do Direito, tão importante quanto afirmar o direito que acreditamos existir é sabermos criticar e refutar o direito afirmado pelo outro.

Proponho esse esquema como base para a construção de uma nova estratégia de ensino-aprendizagem para a área do direito - uma nova forma de estudo, pela qual o aluno aprenda resolvendo problemas, e não mais memorizando conceitos, normas e procedimento - e também pela qual ele aprenda a aprender.

A adoção desse método de ensino-aprendizagem aqui proposto exige agir racionalmente - coloca a necessidade de argumentar no lugar de buscar a adesão afetiva ou ideológica por meio do discurso e da retórica. Segundo Popper (1998):

[...] nossa educação intelectual, assim como nossa educação ética, é corrupta.

É pervertida pela admiração do brilho, do modo por que são ditas as coisas, o que toma o lugar de uma apreciação crítica das coisas que são ditas (e das coisas que são feitas). (p. 284)

Em última instância, sabemos que será sempre necessário decidir entre diferentes possibilidades - decidir é inevitável. Mas devemos chegar a decisões através de argumentos racionais. Para Popper (1975), não há fontes autorizadas do conhecimento - argumentos de autoridade não são argumentos válidos, quer seja com base em autores, quer seja com base em decisões de cortes superiores -, os argumentos apresentados devem ser passíveis de análise crítica, racional. Se não podemos justificar racionalmente uma hipótese (ou teoria), podemos justificar racionalmente uma preferência (POPPER, 1975).

O Debate Crítico Apreciativo (DCA) - denominação utilizada por Popper (2002, p. 24) - permite decidir quais explicações e soluções devem ser inteiramente eliminadas, quais devem ser parcialmente eliminadas e quais sobrevivem, mesmo que provisoriamente.

No âmbito dos processos de produção do conhecimento, é nossa tarefa buscar sempre hipóteses que melhor expliquem os problemas, indicando assim novas alternativas de solução. Essa atitude - denominada por Popper (2006) racionalismo crítico - deve ser a adotada no âmbito do ensino universitário.

A resposta correta à minha pergunta "De que maneira podemos esperar reconhecer e eliminar erros?" parece-me ser: "Pela crítica às teorias e 
conjecturas dos outros e ... pela crítica a nossas próprias teorias e tentativas de solução especulativas”. (De resto, tal crítica de nossas teorias é altamente desejável, mas não indispensável; pois, se não estivermos em condições de fazê-lo, outros o farão por nós).

[...] Esta resposta resume uma posição que poderíamos chamar de "racionalismo crítico" (POPPER, 2006, p. 72, grifo nosso)

Acredito, e muita gente acredita como eu, que todo o ensino de nível universitário (e se possível de nível inferior) devia consistir em educar e estimular o aluno a utilizar o pensamento crítico. (POPPER, 1979, p. 65)

A atitude crítica exigida nesse processo caracteriza-se pela disposição de modificar a hipótese, testá-la e mesmo refutá-la. O senso comum até pode ser o ponto de partida, mas o instrumento do progresso é a crítica. O impacto das teorias sobre nossas vidas pode ser devastador - por isso, é necessário testá-las através da crítica. Ser racional é possuir uma atitude crítica face aos problemas - a atitude crítica é a atitude racional -, uma atitude consciente e crítica de eliminação dos erros (POPPER, 197-b; 1975; 2002).

Em oposição à atitude crítica, há a atitude dogmática, que se caracteriza por buscar confirmar sempre a hipótese aceita e afastar todas as tentativas de refutá-la (POPPER, 197-b). Mesmo assim, não se deve descartar o valor da atitude dogmática; é necessário que o conhecimento seja defendido da crítica sob pena de nenhum conhecimento ser corroborado e ser mantido estável por período de tempo suficiente para que se a sociedade possa utilizá-lo e por meio dele avançar (POPPER, 1975).

Um método de ensino-aprendizagem que propicie o acesso ao conhecimento através do estudo de problemas, como o proposto neste artigo, de um lado permite o reconhecimento da precariedade do conhecimento - visto como provisório -, e de outro possibilita o desenvolvimento da atitude racional e crítica - e com ela a negação do ceticismo e do pessimismo.

A cada passo adiante, a cada problema que resolvemos, não só descobrimos problemas novos e não solucionados, porém, também descobrimos que aonde acreditávamos pisar em solo firme e seguro, todas as coisas são, na verdade, inseguras e em estado de alteração contínua. (POPPER, 1978, p. 13)

Reconhecer que todo o conhecimento é precário, no sentido de que não se pode afirmá-lo como verdade definitiva, mas apenas como verossimilitude, não significa que não se possa produzir conhecimento e mesmo corroborar teorias quando as mesmas não forem refutadas através da crítica intersubjetiva. 
As salas de aula estão tomadas pelo discurso ideológico fácil ou por uma retórica emocional que busca o encantamento. Nesse contexto, a busca pela objetivação do conhecimento através de instrumentos adequados é essencial no âmbito do processo de ensino-aprendizagem. E a crítica intersubjetiva que busca a eliminação de erros dentro de um processo de tentativas de resolução de problemas caminha nesse sentido. A objetividade pura não existe; mas é possível construir um conhecimento objetivo, visto como aquele que resta corroborado - como aproximação da verdade -, por não ter sido falseado.

\subsubsection{A estratégia didático-Pedagógica - o MÉtodo EARP}

A discussão de um problema, no Método EARP, desenrola-se em quatro etapas distintas:

a) Na primeira, a situação problema é apresentada aos alunos, no grande grupo é o momento $P_{1}$ do esquema popperiano. Nesta etapa, devem ocorrer a leitura do enunciado do problema apresentado e a identificação das questões propostas pelo enunciado, bem como o esclarecimento de termos desconhecidos.

b) Na segunda, os alunos buscam identificar cada questão específica nela contida, propondo hipóteses explicativas e identificando/formulando objetivos de aprendizagem - é o momento TE do esquema popperiano, neste caso ampliado para incluir os objetivos de aprendizagem. Esta etapa inclui a apresentação de hipóteses explicativas para as questões identificadas no passo anterior (nesta fase, os alunos se utilizam dos conhecimentos de que já dispõem sobre o assunto); também nessa etapa ocorre a identificação/formulação dos objetivos de aprendizado que permitirão o aprofundamento de seus conhecimentos sobre o tema gerador do problema e as questões que nele estão presentes. A segunda etapa é fundamental para o processo de ensino-aprendizagem: sem a sua adequada realização as etapas seguintes estarão comprometidas.

c) Na terceira, são realizados estudos individuais e/ou em grupos de trabalho, buscando testar as hipóteses propostas e adquirir novos conhecimentos que permitam alcançar os objetivos de aprendizagem - é um primeiro momento de EE no esquema popperiano, ampliado no que se refere ao alcance dos objetivos de aprendizagem.

d) Na quarta, após os estudos individuais e/ou em grupos de trabalho, realizados fora do grande grupo, são rediscutidos em sala de aula, no grande grupo, o problema e as soluções hipotéticas apresentadas, agora à luz dos novos conhecimentos adquiridos - é um segundo momento EE do esquema popperiano, agora com a presença e participação de todos os alunos e com a análise apenas das hipóteses sobreviventes na etapa anterior. É também nesta etapa que há o processo mais aguçado de refutação e corroboração de hipóteses, surgindo então $P_{2}$ (ou $P_{2}, P_{3}, P_{4}$ etc.). 
Nessa divisão, três das quatro etapas ocorrem em sala de aula: as duas primeiras ocupam uma aula, e a quarta e última, uma ou mais aulas - todas essas etapas podem iniciar por um trabalho em pequenos grupos seguido de uma mesa redonda, ou diretamente no grande grupo. Na quarta etapa deve ser elaborado um consolidado final, com a participação de todos - um relatório com as hipóteses refutadas e corroboradas, bem como os motivos dessas conclusões.

Os conhecimentos necessários à resolução de problemas específicos deverão ser aprofundados através de aulas, conferências, palestras, painéis ou seminários oferecidos regularmente. Essas atividades deverão ser desenvolvidas ou coordenadas pelos professores responsáveis e terão a finalidade de aprofundar, organizar e sistematizar o conhecimento adquirido.

O professor, na utilização desse método, deve conhecer muito bem a dinâmica dos grupos de trabalho e estar consciente dos objetivos da disciplina ou do módulo pelo qual é responsável ou corresponsável, efetuando o seu planejamento integral, a preparação adequada de cada uma das aulas e a elaboração de problemas que sejam pertinentes aos conteúdos, competências e habilidades específicos. É também da responsabilidade do professor, ou do conjunto de professores corresponsáveis, a avaliação individual dos alunos e a avaliação crítica da qualidade dos problemas, do planejamento proposto e da realidade efetivamente transcorrida.

São qualidades indispensáveis ao professor, para trabalhar com essa metodologia, o interesse pelo trabalho dos pequenos grupos - quando for o caso - e do grande grupo, o respeito pela opinião dos alunos, a disponibilidade para a orientação e o incentivo à pesquisa. São defeitos o desinteresse pelo trabalho dos grupos, a tendência a simplesmente ministrar aulas sobre o tema e o desconhecimento dos recursos disponíveis para que os alunos possam realizar seus estudos individuais ou em pequenos grupos.

O docente deverá garantir que o grupo ou grupos funcionem, que todos participem e que a discussão não se distancie do tema, de forma que os alunos possam chegar, pelo debate crítico, à refutação ou corroboração das hipóteses inicialmente apresentadas e que os objetivos de aprendizado identificados para aquele problema sejam atingidos. Também é desejável que os grupos de trabalho sejam formados por alunos com diferentes visões de mundo. Segundo Popper (2002):

[...] o debate entre pessoas que perfilhem pontos de vista idênticos ou quase idênticos poderá ser mais fácil do que outro entre pessoas que sustentem opiniões diametralmente opostas ou bastante distintas. Mas só neste último caso é que a discussão originará algo com interesse. [...] Mesmo não se chegando a acordo, as pessoas sairão mais esclarecidas do debate do que ao iniciá-lo. (p. 160) 
Quando o grande grupo for dividido, os grupos de trabalho devem ser compostos de quatro a seis alunos. Entre estes, um será o coordenador e outro, o secretário, em cada sessão de trabalho. Deve haver o rodízio dos papéis de coordenador e de secretário, entre os alunos de cada grupo, a cada sessão, permitindo que todos os exerçam - o exercício dessas atividades permite o aprendizado de competências e habilidades específicas.

Nessa opção metodológica, com a divisão do grande grupo em outros menores, os alunos coordenadores de cada grupo de trabalho devem garantir que a discussão do problema se dê de forma metódica e que todos os membros dos grupos de trabalho participem dela. Já o aluno secretário deve garantir que as várias etapas da discussão do grupo sejam convenientemente anotadas para serem relatadas no grande grupo, de forma que o grupo não se perca na discussão e que não volte a pontos já discutidos anteriormente.

Quando não houver a divisão do grande grupo em grupos menores, poderá ou não ocorrer a indicação de um aluno coordenador e de um aluno secretário, com as mesmas funções já indicadas. Não ocorrendo, o professor terá de exercer essas funções, ou apenas uma delas, indicando um aluno para a outra, ou utilizando um monitor ou estagiário.

Para que o processo de ensino-aprendizagem seja positivo, é fundamental que todos os alunos estudem e participem ativamente, propiciando uma boa discussão do problema e das hipóteses explicativas, de forma metódica, respeitando as diretrizes definidas pelo professor ou coordenador do grupo.

A terceira etapa, o estudo individual ou em grupos de trabalho, desenrola-se preferencialmente como atividade extraclasse. Os alunos, para isso, recebem orientações sobre os recursos de aprendizado à sua disposição (livros, periódicos, filmes, vídeos, páginas da internet, blogs, docentes consultores etc.). $\mathrm{O}$ uso desses recursos é de inteira responsabilidade dos alunos e grupos de trabalho, que têm total liberdade. Os discentes poderão também optar pela busca de outros recursos além daqueles expressamente indicados, respeitando sempre os objetivos de aprendizado propostos dentro do grande grupo.

É necessário destacar que, em todas as etapas do método apresentado, há a necessidade de manter a postura crítica e antidogmática. Segundo Popper (197-b):

[...] a atitude dogmática está claramente relacionada com a tendência para verificar nossas leis e esquemas, buscando aplicá-los e confirmá-los sempre, a ponto de afastar as refutações, enquanto a atitude crítica é feita de disposição para modificá-los - a inclinação no sentido de testá-los, refutando-os se isso for possível. (p. 80, grifo do autor)

Relativamente à avaliação dos conteúdos, devem ser adotadas estratégias que possibilitem verificar se os objetivos de aprendizagem foram efetivamente alcançados; já 
a avaliação de competências e habilidades é mais efetiva se for realizada por meio da observação metódica do desempenho do aluno na resolução dos problemas propostos para a fase do curso em que se encontra. Não devem ser excluídas outras modalidades as quais possam ser utilizadas conjuntamente - nenhuma forma de avaliação precisa ser descartada, devendo as escolhas levarem em consideração sua adequação ao processo ensino-aprendizagem como um todo.

É de se destacar que a utilização do esquema popperiano no processo educacional - em especial nos cursos de graduação - não ocorre exatamente com as mesmas finalidades que no processo de pesquisa científica - característico dos cursos de pósgraduação stricto sensu, em especial os programas de doutorado.

$\mathrm{Na}$ pesquisa científica, a regra é trabalhar com problemas para os quais ainda não se tem respostas ou com problemas para os quais as respostas existentes são insuficientes ou se mostraram inadequadas.

Já no processo de ensino-aprendizagem dos cursos de graduação, os problemas, em regra geral, são construídos para que os alunos encontrem respostas pré-existentes para problemas para os quais já há hipóteses corroboradas - embora não seja impossível a construção de novas hipóteses. Como diz Popper (1981; 197-b), não há oposição entre tradição e crítica; a tradição é condição para a crítica - a vida social exige tradição. Nesse sentido, a recuperação histórica das discussões, legislações, decisões e seus reflexos na vida social é de suma importância no processo de refutação.

Mesmo nessa situação, a proposta popperiana parece adequada por integrar momentos fundamentais, hoje dispersos no âmbito do processo de ensino-aprendizagem: o primeiro é a busca de solução de problemas, o segundo é a utilização de um instrumental crítico e racional, e o terceiro é a objetivação do conhecimento que ocorre durante o processo como um todo - objetivação essa que se dá no processo de crítica recíproca, na busca de resolução dos problemas. A objetividade do conhecimento é "o resultado social de sua crítica recíproca” (POPPER, 1978, p. 23).

\section{Segundo PASSo: ReOrganizar os cursos - o Projeto Pedagógico EARP}

O projeto pedagógico se constitui no planejamento que uma instituição de ensino superior faz para um determinado curso. Nele, além de listar disciplinas ou módulos e demais atividades que compõem o currículo pleno, também são indicados os meios pelos quais se trabalharão os conteúdos e se desenvolverão as competências e habilidades durante o curso e como será atingida a formação que efetivamente materializará o perfil proposto, considerando as necessidades profissionais da área específica.

Os projetos pedagógicos existentes estão, de modo geral, estruturados para materializar o currículo mínimo, ou seja, o conjunto de conteúdos e demais atividades obrigatórios pela legislação em vigor, e são, por isso, denominados tradicionais. 
Contemplam, dessa forma, a listagem de disciplinas ou módulos que contêm os conteúdos mínimos definidos nas diretrizes curriculares - com as respectivas ementas e a listagem das demais atividades obrigatórias - acompanhadas de suas respectivas regulamentações -, que atualmente, para os cursos de Direito, são as atividades complementares, o estágio supervisionado e o trabalho de curso.

Dois dos principais problemas dos projetos pedagógicos tradicionais são a falta de integração entre as disciplinas ou os módulos - principalmente entre as do eixo fundamental e aquelas dos eixos profissional e prático - e a excessiva autonomia do docente ante sua disciplina ou seu módulo. As avaliações, acompanhando esses problemas, são, geralmente, restritas à esfera cognitiva, administradas apenas pelo docente que as faz, segundo seu critério de importância, muitas vezes exigindo esforço descabido ou esforço insuficiente por parte do aluno e resultando, respectivamente, na prática de estratégias pedagógicas terroristas ou no pacto de mediocridade. $\mathrm{Ou}$ seja, na prática o modelo tradicional de projeto pedagógico é pulverizado, possuindo cada membro do corpo docente o seu próprio projeto.

Contemporaneamente houve-se falar em projeto pedagógico por competências e habilidades. A materialização desse modelo, entretanto, não tem ido além de um projeto pedagógico tradicional ao qual se adicionam as competências e habilidades que deverão ser adquiridas pelos alunos. Em grande parte desses projetos sequer é indicado como será trabalhado o desenvolvimento dessas competências e habilidades e como será atingida a formação profissional adequada ao perfil proposto para o egresso.

Ou seja, nessa espécie de projeto, as competências e habilidades são ainda desenvolvidas fundamentalmente dentro de um currículo pleno, definido sob a forma de uma lista de disciplinas ou módulos e atividades. Elas são trabalhadas de forma compartimentalizada por cada professor em seu espaço de domínio, quando não constam apenas formalmente do projeto pedagógico.

Buscando soluções para esses e outros problemas do processo de ensino-aprendizagem existentes nos cursos de Direito, esboço, na sequência, uma proposta de organização curricular dos cursos, a ser utilizada conjuntamente com o método proposto na parte 2. O processo de Ensino-Aprendizagem pela Resolução de Problemas é a integração desses dois elementos: nova concepção de currículo e nova estratégia didático-pedagógica.

\section{I O Currículo EARP}

Um currículo pensado para viabilizar o EARP necessita apresentar seus conteúdos ao aluno de modo integrado e integrador dos conhecimentos. Não deve ocorrer, portanto, a divisão do currículo em disciplinas, mas sim em módulos temáticos interdisciplinares - a interdisciplinaridade deve ser real e não apenas formal. Também não deve ocorrer a divisão clássica entre ciclo básico e ciclo profissional a divisão entre os conteúdos dos eixos fundamental e profissional, ou a divisão entre 
conteúdos teóricos e práticos. A integração dos conteúdos deve ocorrer nos temas, e o aprendizado, pelo método de tentativa e erro, na busca de soluções para problemas teóricos e práticos.

Parafraseando e citando Popper (197-b), pode-se dizer que a ideia de que o direito, a filosofia, a sociologia, a política, a economia, a antropologia, a psicologia e a história existem por si mesmas:

[...] como campos de estudo ou 'disciplinas' distinguíveis entre si pela matéria que investigam, parece-me resíduo da época em que se acreditava que qualquer teoria precisava partir de uma definição do seu próprio conteúdo. Na verdade não é possível distinguir disciplinas em função da matéria de que tratam; elas se distinguem umas das outras em parte por razões históricas e de conveniência administrativa (como a organização do ensino e do corpo docente), em parte as teorias que formulamos para solucionar nossos problemas tem a tendência de se desenvolver sob a forma de sistemas unificados. Mas essa classificação e essas distinções são superficiais e têm relativamente pouca importância. Estudamos problemas, não matérias: problemas que podem ultrapassar as fronteiras de qualquer matéria ou disciplina. (p. 95-6, grifo do autor)

No currículo tradicional, os campos de estudos estão representados pelo conjunto de disciplinas; no Currículo EARP, estão identificados pelo conjunto de temas de estudo, agrupados em módulos temáticos, por afinidades, sendo cada tema desdobrado em situações-problema que o aluno deve estudar, analisar e buscar resolver. Em qualquer dessas situações é necessário, entretanto, considerar que o currículo não poderá esgotar todo o conteúdo da área dentro do tempo de duração do curso de graduação.

Em um Projeto Pedagógico EARP, o tema é a estrutura mínima em torno da qual se aglutinam os conteúdos, as competências e as habilidades. O currículo, portanto, é estruturado por meio de módulos temáticos que se constituem de conteúdos afins. Um módulo temático não é uma matéria ou disciplina, mas contém conteúdos de várias matérias ou disciplinas, necessários para o entendimento de uma situação dada.

Os módulos temáticos devem reunir temas derivados do conjunto de conhecimentos, competências e habilidades previstos como necessários para a formação do profissional pretendido pelo currículo. Os temas serão apresentados aos alunos por meio de problemas.

É recomendável adotar avaliações progressivas - avaliações gerais -, em intervalos regulares, com a finalidade de acompanhar o progresso da aquisição de conhecimentos por parte dos alunos. Um dos modelos possíveis de avaliação progressiva é a aplicação de prova comum a todos os alunos, independentemente da fase 
em que se encontrem, com um número fixo de questões-problema as quais versem sobre todos os conteúdos do curso e testem a aquisição e o desenvolvimento de competências e habilidades.

O gerenciamento de um currículo por EARP é uma atividade intensiva e contínua. Considerando as exigências do Sistema Nacional de Avaliação do Ensino Superior (SINAES), deve ser entregue ao denominado Núcleo Docente Estruturante (NDE) do curso, mas implica também em uma articulação de todo o corpo docente, tanto em sentido vertical (os docentes que trabalham com os mesmos conteúdos temáticos, mas em blocos sequenciais), como em sentido horizontal (os docentes que trabalham com diferentes conteúdos temáticos, articulados de forma interdisciplinar dentro de um mesmo bloco ou em blocos coexistentes no mesmo período letivo).

A participação do docente ocorre pelo tempo de um módulo temático, no qual são discutidos temas afins, e que tem sua duração definida, considerando o tema específico. O docente, nesse contexto pedagógico, deve saber trabalhar em grupo, tendo em vista que um mesmo módulo temático envolverá necessariamente, pelas suas características interdisciplinares, um conjunto de áreas diferentes, mesmo que afins.

Em artigo anterior, apresentei e defendi a adoção do Problem Based Learning como nova forma de organização curricular. Entretanto, percebo agora que o PBL propõe uma estrutura de funcionamento em termos de comissões e um número de alunos por tutor que são irreais para a nossa realidade, considerando o grande aumento de custos envolvido. A proposta que agora denominei EARP tenta evitar esse e outros problemas, por meio de mudanças metodológicas e pedagógicas que me parecem mais adequadas aos cursos de direito.

\subsection{Proposta de currículo EARP para cursos de Direito}

Nos itens a seguir é apresentado um exercício, uma tentativa de dar visibilidade à forma que uma grade curricular teria no âmbito de um Projeto Pedagógico EARP.

\subsection{O currículo de um curso de Direito com Projeto Pedagógico EARP}

A grade curricular apresentada (tabela 1) está estruturada considerando grandes áreas do direito e elimina a divisão entre direito material e direito processual. Também elimina a organização tradicional em uma série de disciplinas; opta-se por dois grandes temas (ou conjuntos de conteúdos) por ano, os quais serão trabalhados de forma interdisciplinar e integrada, devendo também contemplar, obrigatoriamente, os temas transversais. 
Tabela 1 - Proposta de grade curricular para um curso de direito com Projeto Pedagógico EARP

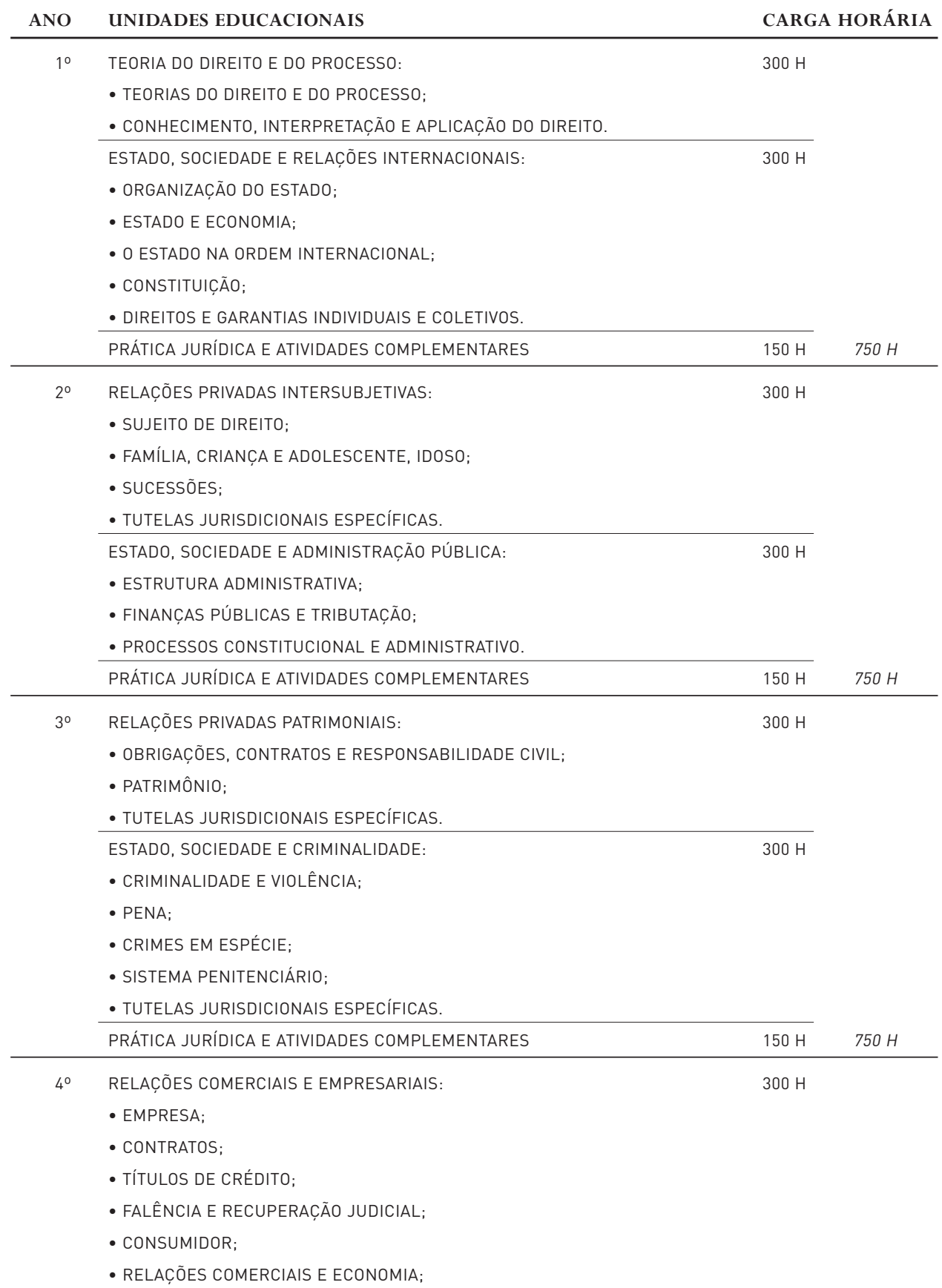


- TUTELAS JURISDICIONAIS ESPECÍFICAS

RELAÇ̃̃ES DE TRABALHO E PREVIDENCIÁRIAS:

- RELAÇÃO de tRABALHO;

- ACIDENTES DE TRABALHO;

- SEGURIDADE SOCIAL,

- MUNDO DO TRABALHO, PREVIDÊNCIA SOCIAL E ECONOMIA;

- TUTELAS JURISDICIONAIS ESPECÍFICAS.

$50 \mathrm{H} \quad 750 \mathrm{H}$

$5^{\circ}$ DIREITOS CONTEMPORÂNEOS:

$300 \mathrm{H}$

- BIOÉTICA;

- MUNDO digItAL, REALIDAdE VIRTUAL E COMUNICAÇÃo POR MEIO ELETRÔNICO;

- INTEGRAÇÃo PLANETÁRIA;

- NOVAS REALIDADES EMERGENTES.

\begin{tabular}{lll}
\hline MÓDULO ELETIVO & $300 \mathrm{H}$ \\
\hline PRÁTICA JURÍDICA E ATIVIDADES COMPLEMENTARES & $150 \mathrm{H}$ & $750 \mathrm{H}$
\end{tabular}

QUESTÕES E TEMAS TRANSVERSAIS:

- PERCEPCÕES HISTÓRICA, POLÍTICA, ECONÔMICA, SOCIOLÓGICA, FILOSÓFICA, ÉTICA, ANTROPOLÓGICA E PSICOLÓGICA;

- SOLIDARIEDADE E RESPONSABILIDADE SOCIAL;

- MEIO AMBIENTE;

- ACESSO À JUSTIÇA.

\subsubsection{A semana padrão de um curso de Direito EARP}

A organização da semana letiva de um curso de Direito com projeto pedagógico EARP pode, exemplificativamente, ser realizada nos moldes dos quadros 1 e 2.

Quadro 1 - Horário 1: maior presença de metodologias ativas (mais próximo do PBL)

\begin{tabular}{|c|c|c|c|c|c|}
\hline SEGUNDA-FEIRA & TERÇA-FEIRA & QUARTA-FEIRA & QUINTA-FEIRA & SEXTA-FEIRA & SÁBADO \\
\hline AULAS E/OU & HORÁRIO & AULAS E/OU & HORÁRIO & ESTUDO DE & ATIVIDADES \\
\hline CONFERÊNCIAS & PRÓ-ALUNO & CONFERÊNCIAS & PRÓ-ALUNO & PROBLEMAS & COMPLEMENTARES \\
\hline PRÁTICA & HORÁRIO & PRÁTICA & HORÁRIO & ESTUDO DE & ATIVIDADES \\
\hline JURÍDICA & PRÓ-ALUNO & JURÍDICA & PRÓ-ALUNO & PROBLEMAS & COMPLEMENTARES \\
\hline
\end{tabular}

Quadro 2 - Horário 2: menor presença de metodologias ativas (mais próximo de um modelo híbrido)

\begin{tabular}{|c|c|c|c|c|c|}
\hline SEGUNDA-FEIRA & TERÇA-FEIRA & QUARTA-FEIRA & QUINTA-FEIRA & SEXTA-FEIRA & SÁBADO \\
\hline AULAS E/OU & HORÁRIO & AULAS E/OU & HORÁRIO & ESTUDO DE & ATIVIDADES \\
\hline CONFERÊNCIAS & PRÓ-ALUNO & CONFERÊNCIAS & PRÓ-ALUNO & PROBLEMAS & COMPLEMENTARES \\
\hline AULAS E/OU & PRÁTICA & AULAS E/OU & PRÁTICA & ESTUDO DE & ATIVIDADES \\
\hline CONFERÊNCIAS & JURÍDICA & CONFERÊNCIAS & JURÍDICA & PROBLEMAS & COMPLEMENTARES \\
\hline
\end{tabular}


Como se percebe: (a) na primeira proposta de horário, as reuniões de estudo de problemas e os horários de estudos independentes ocupam grande parte do tempo do curso; e (b) na segunda proposta há um equilíbrio entre metodologias ativas e aulas e conferências. A definição de como articular as diversas atividades dentro do horário apenas pode ocorrer em cada projeto específico.

Os quadros apresentados acima têm apenas a intenção de demonstrar, de forma clara, que o currículo apresentado é flexível relativamente à sua implementação, permitindo inclusive a substituição gradativa das metodologias tradicionais pelas metodologias ativas.

Não há como oferecer uma receita acabada de organização dos horários e distribuição das atividades - inclusive porque os horários foram apresentados considerando um curso de cinco anos, com carga horária mínima (em horas-relógio, 60 minutos), funcionando em turno único (de segunda a sexta-feira), com aulas aos sábados, e vinte semanas letivas; um curso com maior carga horária e com aulas em dois turnos teria outra configuração, assim um curso sem aulas aos sábados, por exemplo.

\section{O PROBlema, A TENTATIVA, O ERRO, A APRENDiZAgEM - A PROPOSTA APRESENTADA E A NECESSIDADE DE SUA CRÍTICA}

A proposta apresentada neste artigo, como indicado desde o seu início, se desdobra em dois momentos, a saber: a forma de ensinar e aprender - o método de ensino e a forma de organizar os conteúdos, as habilidades e as competências que compõem o curso - o projeto pedagógico e o currículo.

A ideia central, que deve ser creditada a Karl Popper e que está presente na proposta como um todo, é a da necessidade de trabalhar, no processo de ensino-aprendizagem, com a busca de solução de problemas, teóricos e práticos.

Subjacente a essa ideia está outra, a de que se aprende por tentativa e erro - ideia também trazida da obra popperiana. Segundo essa concepção aprendemos à medida que, diante de problemas, conjecturamos soluções, as quais testamos. E através desses testes vamos afastando as hipóteses erradas e mantendo - mesmo que provisoriamente - aquelas que não apresentarem um resultado negativo.

Essa ideia, transposta para o processo de ensino-aprendizagem, considera que a grande tarefa da educação é preparar o ser humano para resolver os problemas que surgirão durante a sua vida - pessoais, profissionais, ou outros. E, como não é possível garantir que as soluções encontradas são verdadeiras, mesmo que adequadas para o momento de sua proposição, a solução é que ele aprenda a eliminar os erros, afastando as hipóteses as quais não resolvem o problema e mantendo, como soluções provisórias, aquelas que o resolvem.

A utilização desse método também demonstra que a solução de um problema sempre gera novos problemas, os quais também necessitam de solução, e assim por 
diante. Essa constatação evidencia a importância de desenvolver as habilidades e competências necessárias para a resolução de problemas, e não a acumulação de conteúdos, como faz a educação tradicional.

Além dessas questões, atinentes em especial ao método de ensino-aprendizagem, é também necessário que se organize o processo educacional, de forma que o aluno vá gradativamente acessando os conhecimentos e desenvolvendo as competências e habilidades necessárias à solução dos problemas.

Essa organização exige uma nova forma de estruturar os currículos dos cursos, considerando que os problemas do mundo - tanto os teóricos como os práticos - não se esgotam nos limites de disciplinas específicas, mas exigem conhecimentos de várias áreas. Surge daí a necessidade de estruturar também uma proposta para repensar os projetos pedagógicos, por temas interdisciplinares organizados em módulos.

A proposta integral - incluindo o método e o projeto pedagógico - denominei Ensino-Aprendizagem pela Resolução de Problemas. Espero que ela instigue os pesquisadores da área de educação, em especial aqueles preocupados com o ensino do direito, a realizar suas observações e críticas, ajudando a corroborar ou refutar minhas conjecturas.

: ARTIGO APROVADO (16/05/2010) : RECEBIDO EM 01/10/2009

\section{NOTAS}

1 Sobre uma proposta de PBL para os cursos de Direito, ver Rodrigues, Horácio Wanderlei, Pensando o projeto pedagógico dos Cursos de Direito, Anuário da ABEDi, Florianópolis, Fundação Boiteux, v. 4, n. 4, p. 269-86, 2006.

\section{REFERÊNCIAS BIBLIOGRÁFICAS}

POPPER, Karl. A lógica da pesquisa científica. São Paulo: Cultrix, 197-a. Conjecturas e refutações. Brasília: UnB, 197-b.

. Conhecimento objetivo. Belo Horizonte: Itatiaia; São Paulo: EDUSP; 1975.

. A lógica das ciências sociais. Rio de Janeiro: Tempo Brasileiro; Brasília: UnB; 1978.

. A ciência normal e seus perigos. Em LAKATOS, Imre; MUSGRAVE, Alan (Orgs.). A crítica e o

desenvolvimento do conhecimento. São Paulo: Cultrix; EDUSP, 1979. p. 63-71.

A miséria do historicismo. São Paulo: Cultrix; EDUSP, 1980.

. O racionalismo crítico na política. Brasília: UnB, 1981.

. A sociedade aberta e seus inimigos. Belo Horizonte: Itatiaia; São Paulo: EDUSP, 1998. p. 267-89. 
O conhecimento e o problema corpo-mente. Lisboa: Edições 70, 2002.

Em busca de um mundo melhor. São Paulo: Martins Fontes, 2006.

RODRIGUES, Horácio Wanderlei. Pensando o Ensino do Direito no Século XXI: diretrizes curriculares, projeto pedagógico e outras questões pertinentes. Florianópolis: Fundação Boiteux, 2005.

Pensando o projeto pedagógico dos Cursos de Direito. Anuário da ABEDi, Florianópolis, Fundação Boiteux, v. 4, n. 4, p. 269-86, 2006.

UNIVERSIDADE ESTADUAL DE LONDRINA (UEL). Centro de Ciências da Saúde. Curso de Medicina. Problem Based Learning. Disponível em: <http://www.uel.br/ccs/pbl>. Acesso em: 21 ago. 2005.

\section{Horácio Wanderlei Rodrigues}

Campus Universitário

Trindade - 88040-900

Florianópolis - SC - Brasil

horaciowrlaccj.ufsc.br
Pós-DOUTOR PELA UNIVERSIDADE dO Vale do Rio dos Sinos (Unisinos)

MESTRE E DOUTOR EM DIREITO PELA Universidade Federal de Santa CATARINa (UFSC)

Professor titular do dePARTAMENTO de Direito dA Universidade Federal de Santa Catarina (UFSC) 